\title{
Visible-Light-Driven Photocatalytic Degradation of Aniline over $\mathrm{NaBiO}_{3}$
}

\author{
Guo Liu, ${ }^{1,2}$ Zhen Wang, ${ }^{2,3}$ Wenjie Zheng, ${ }^{2}$ Shaogui Yang, ${ }^{1}$ and Cheng Sun ${ }^{1}$ \\ ${ }^{1}$ School of the Environment, Nanjing University, Nanjing 210093, China \\ ${ }^{2}$ State Key Laboratory of Geohazard Prevention and Geoenvironment Protection, Chengdu University of Technology, \\ Chengdu 610059, China \\ ${ }^{3}$ Faculty of Geosciences and Environmental Engineering, Southwest Jiaotong University, Chengdu 610059, China
}

Correspondence should be addressed to Shaogui Yang; yangdlut@126.com and Cheng Sun; envidean@nju.edu.cn

Received 6 December 2013; Accepted 1 January 2014; Published 13 February 2014

Academic Editor: Haimin Zhang

Copyright (c) 2014 Guo Liu et al. This is an open access article distributed under the Creative Commons Attribution License, which permits unrestricted use, distribution, and reproduction in any medium, provided the original work is properly cited.

\begin{abstract}
Aniline was almost completely degraded in $30 \mathrm{~min}$ in given conditions. It was found that $\mathrm{pH}$ and $\mathrm{NaBiO}_{3}$ dosage had played important role in the photocatalytic degradation. To scrutinize the mechanistic details of the aniline photodegradation, several critical analytical methods including spectroscopy and GC/MS were utilized to detect the temporal course of the reaction. Intermediates and several small molecular products were separated and identified, such as $\mathrm{C}_{2} \mathrm{H}_{5} \mathrm{O}_{3} \mathrm{~N}_{,} \mathrm{C}_{10} \mathrm{H}_{13} \mathrm{O}_{2} \mathrm{~N}$, and $\mathrm{C}_{12} \mathrm{H}_{10} \mathrm{~N}_{2}$. Then two possible photodegradation pathways of aniline over $\mathrm{NaBiO}_{3}$ were proposed: ring opening and mineralization.
\end{abstract}

\section{Introduction}

Aniline is widely used in the chemical industry, mainly as a raw material for obtaining isocyanate. Aniline is also applied to the manufacture of accelerators, antioxidants, pesticides, dyes, and pigments [1]. The negative effects of aniline on human health and the environment are depending on the amount and exposure time. Aniline can enter the aqueous environment via dyes and nitro aromatic compounds and has been identified as a potential carcinogen [2]. Nowadays, more attention is focused to remove it from environment.

Among chemical methods, photocatalysis technology can play an important role in removing harmful organic compounds, which enables human to have comfortable and safe lives [3]. Being the most common photocatalyst among semiconductors, $\mathrm{TiO}_{2}$ possesses various merits such as low cost, high photocatalytic activity, chemical activity, and nontoxicity [4]. As its photoresponse is only limited in the UV region, which accounts for less than $5 \%$ of the earth-reaching solar irradiation $[5,6]$, it requires a high power UV excitation source [7]. Therefore, it is meaningful to explore a new photocatalyst which can utilize visible light.
Lots of studies have been devoted to developing visible-lightdriven photocatalysis. Apart from $\mathrm{TiO}_{2}$ doped with metallic elements, for instance, $\mathrm{Cr}^{3+}$ and $\mathrm{V}^{5+}[8]$, new materials such as $\mathrm{AgNbO}_{3}$ and $\mathrm{InNbO}_{4}$ are previously reported to absorb visible light $[9,10]$. However, the activity of the photocatalyst was hardly enhanced, and the low reaction rate severely blocked the development of photocatalysis technology.

Seeking for new materials with higher photocatalytic activity has become a key solution to this problem. Particularly, $\mathrm{Bi}(\mathrm{V})$-containing oxides are potential materials as the candidates of visible light sensitive oxides [11]. In fact, some $\mathrm{Bi}(\mathrm{V})$-containing oxides have indicated the ability of absorption of visible light. Among them, $\mathrm{NaBiO}_{3}$ is studied as it displayed the visible light absorption because of its hybridized valence band. The large dispersion of the hybridized orbitals in the conduction band increases the mobility of the photoexcited electrons, thus suppressing the recombination of photoexcited electron-hole pairs and enhancing activities [11]. Kou and coworkers [12] utilized $\mathrm{NaBiO}_{3}$ in photooxidation of PAHS. Yu and coworkers [13] utilized $\mathrm{NaBiO}_{3}$ in photooxidation of rhodamine $\mathrm{B}$ under visible light irradiation and found that heating temperature 


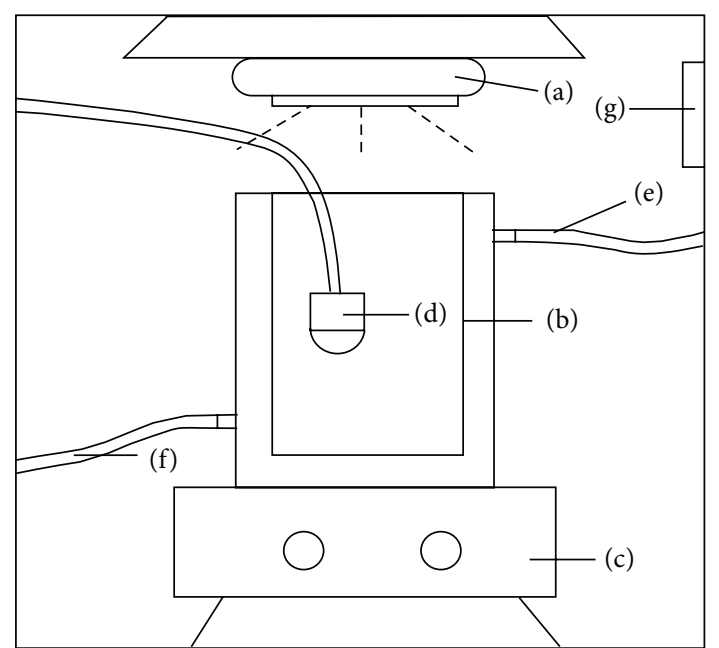

Figure 1: Photoreaction chamber. (a) Xenon lamp, (b) double-deck beaker, (c) magnetic stirrer, (d) oxygen pump, (e) outlet, (f) inlet, and (g) fan.

significantly influenced the photocatalytic activity of the catalyst. As $\mathrm{NaBiO}_{3}$ has the properties of strong oxidation, electromagnetism, and electrochemical activity, it has been applied to industries such as organic synthesis, superconductor, and electrochemistry [14]. It is meaningful to explore the feasibility of the photodegradation of aniline over $\mathrm{NaBiO}_{3}$.

In this study, aniline was chosen as the target organic pollutant to investigate its degradation behavior over $\mathrm{NaBiO}_{3}$ under visible light irradiation. The goal was aimed at the investigation of aniline degradation and the presentation of mechanistic details of the photochemical process.

\section{Experimental Section}

2.1. Materials and Reagents. Aniline was bought from Ke Long Chemical Company, and $\mathrm{NaBiO}_{3} \cdot 2 \mathrm{H}_{2} \mathrm{O}(\mathrm{NBH})$ was purchased from Guang Fu Chemical Products Institute. All other chemicals were of analytical grade and used without further purification.

2.2. Photoreaction Chamber. Photodegradation experiments were performed in a chamber which was displayed in Figure 1. A $500 \mathrm{~W}$ xenon lamp (Chengdu Na Pu Photoelectricity Company, China) was positioned to ensure visible light. The reactor was a double-deck beaker equipped with an inlet and an outlet which can draw into water circulation to make sure experiments performed in adequate temperature. A $50 \mathrm{~W}$ fan was used to keep the chamber at ambient temperature. A stir was used to ensure that photocatalyst distributes well in the suspension. Oxygen pump was used to provide enough oxygen to ensure that oxidation performed sufficiently.

2.3. Experimental Procedures and Analysis Methods. In the experiments, the dispersions containing aniline and $\mathrm{NaBiO}_{3}$ photocatalyst were prepared by adding $\mathrm{NBH}$ to an aqueous solution of aniline in a beaker.

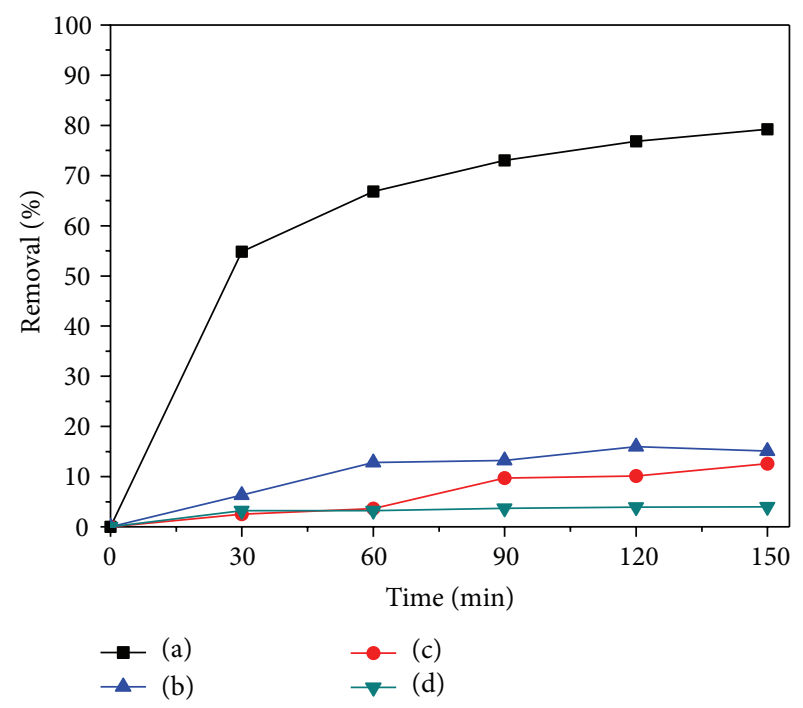

FIGURE 2: Control experiment. (a) Light+ NBH, (b) NBH alone, (c) light alone, and (d) none.

A $500 \mathrm{~mL}$ double-deck beaker was used as a reactor. The NBH was added to $200 \mathrm{~mL}$ aniline solution, which was magnetically stirred at a constant speed to ensure continuous contact between the solution and $\mathrm{NaBiO}_{3}$ when they were under visible light irradiation emitted from xenon lamp. At given time intervals, samples $(10 \mathrm{~mL})$ were centrifuged immediately. The samples were analyzed by a V-1100D spectrophotometer. The intermediates were detected by GC/MS (GCMS-QP2010 Plus).

\section{Results and Discussions}

3.1. Control Experiment. The decreases of aniline concentration as a function of reaction time were shown in Figure 2. In the control experiment, when utilizing NBH $(1 \mathrm{~g} / \mathrm{L})$ alone, a slight decrease of aniline concentration was observed; this could be attributed to surface adsorption. Aniline was relatively stable in aqueous solution under visible light irradiation as expected. Therefore, aniline was not significantly decomposed by either under ambient conditions used in the experiment. Aniline can be degraded rapidly only in the circumstance of both $\mathrm{NBH}$ and visible light irradiation.

3.2. Nitrogen Transformation. As there is an amidogen in the aniline structure, it will be harmful to environment if it transforms into nitrite nitrogen. It is important to study the transformation of nitrogen in the photodegradation process of aniline.

As it was shown in Figure 3, the removal rose in the first $30 \mathrm{~min}$ of the degradation aniline; the concentration of ammonia nitrogen and nitrate were increasing and tended towards stability in $120 \mathrm{~min}$. Nitrites were produced as the intermediates of nitrate, and the concentration was low on the whole. 


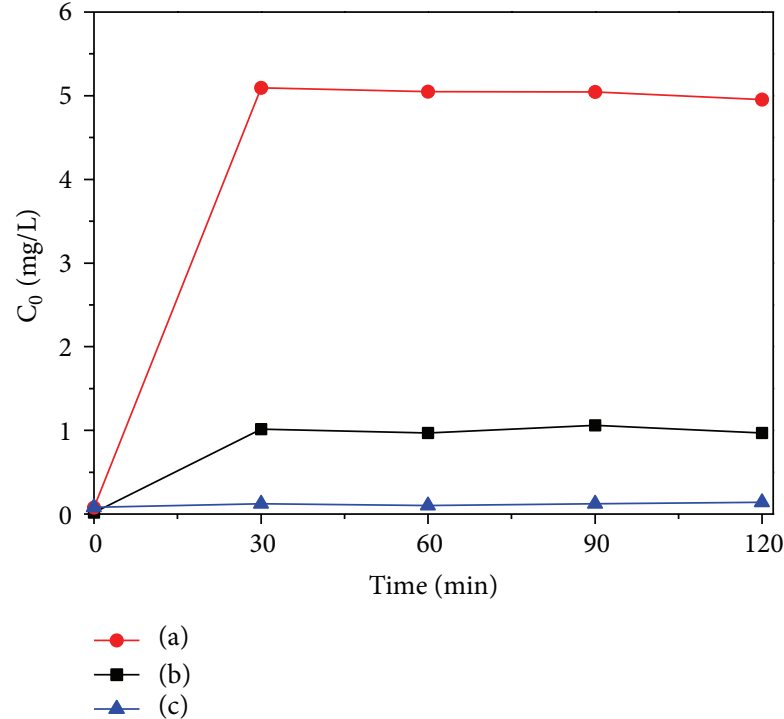

FIGURE 3: Temporal change in the concentration of nitrogen during the photodegradation. (a) Nitrate, (b) ammonia nitrogen, and (c) nitrite.

3.3. Kinetic Model. The reaction mechanism of photocatalytic degradation was the process of absorption-surface-reactiondesorption whose kinetic model was in coincidence with the Langmuir-Hinshelwood model $[15,16]$. The kinetic model was as below [17]:

$$
-\frac{d c}{d t}=K c
$$

where $t$ is time and $c$ is instantaneous concentration of aniline. The equation below is the integration of it when $t$ is from 0 to $t$ :

$$
\ln c=-K t+\ln c_{0} .
$$

When initial aniline concentration was $30 \mathrm{mg} / \mathrm{L}$, the pseudo first order rate constant for photocatalytic degradation, light reaction, and dark reaction was $0.0402 \mathrm{~min}^{-1}$, $0.00182 \mathrm{~min}^{-1}$, and $0.000987 \mathrm{~min}^{-1}$, respectively. The kinetic study proved that the effect of $\mathrm{NBH}$ on aniline degradation is great.

\subsection{Influence Factors}

3.4.1. pH Value Effect. In the photocatalytic oxidation, the solution $\mathrm{pH}$ had an instant influence on the agglomeration of particles, electric charge, and absorption of organic on the surface [18]. In Figure 4, the remainder aniline in the acidity was less than that in the neutral and alkaline condition. When $\mathrm{pH}$ was 2 , the aniline concentration was reduced to $0.98 \mathrm{mg} / \mathrm{L}$ in the $120 \mathrm{~min}$ with a removal of $97 \%$. The main reason was that the oxidation was in the dominant position. It was found that the $\mathrm{NBH}$ effect was better in the acidity condition. The removal rate can reach $75 \%$ in the 5 minutes, whereas the removal rate in the neutral and alkaline condition was $20 \%$ and $16 \%$, respectively. In the acidity condition, $\left[\mathrm{BiO}_{3}\right]$

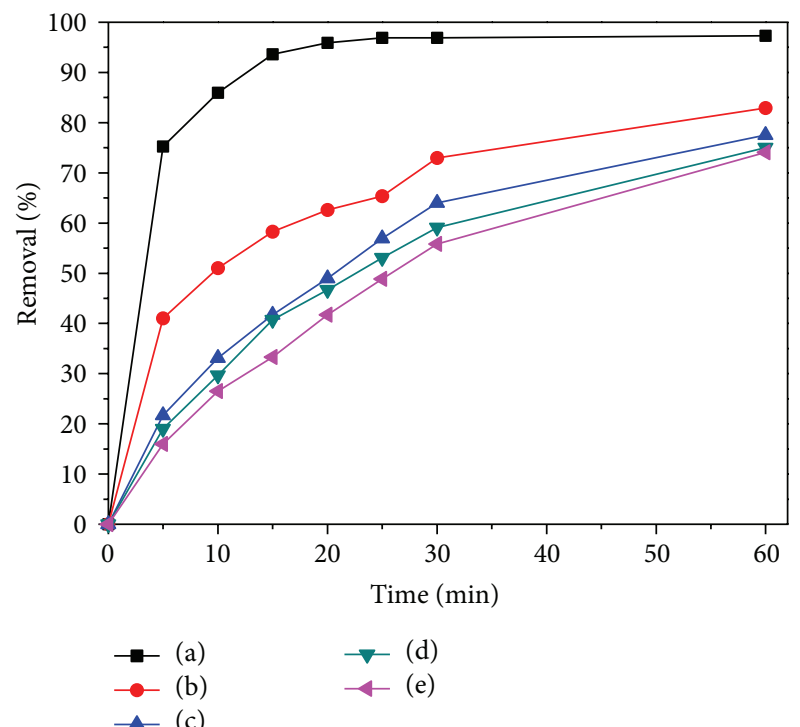

Figure 4: Effect of initial $\mathrm{pH}$ value. (a) $\mathrm{pH}=2$, (b) $\mathrm{pH}=4$, (c) $\mathrm{pH}=8$, (d) $\mathrm{pH}=6$, and (e) $\mathrm{pH}=10$.

can turn into $\left[\mathrm{BiO}_{6}\right]$ more easily, while the latter's crystal structure was relatively weak. During reduction of $\mathrm{Bi}(\mathrm{V})$, oxygen which had higher activity was released [13]. The equation was as below:

$$
\begin{aligned}
2 \mathrm{Bi}(\mathrm{V})-\mathrm{O}^{2-} & \longrightarrow 2 \mathrm{Bi}(\mathrm{IV})-\mathrm{O}^{-} \longrightarrow \mathrm{Bi}(\mathrm{IV})-\mathrm{O}_{2}{ }^{2-} \mathrm{Bi}(\mathrm{IV}) \\
& \longrightarrow \mathrm{Bi}(\mathrm{IV})-\mathrm{O}_{2}{ }^{-}+\mathrm{Bi}(\mathrm{III}) \\
& \longrightarrow 2 \mathrm{Bi}(\mathrm{III})+\mathrm{O}_{2}
\end{aligned}
$$

In this case, aniline was oxidized mainly by $\mathrm{O}_{2}{ }^{\bullet}$. The reaction progress was not part of photocatalytic oxidation.

The photocatalytic oxidation of aniline was as below:

$$
\begin{gathered}
\mathrm{O}_{2}^{\cdot-}+\mathrm{H}^{+} \longrightarrow \mathrm{OOH}^{\bullet} \\
\mathrm{C}_{6} \mathrm{H}_{5} \mathrm{NH}_{2}+\mathrm{O}_{2}^{\cdot-} / \mathrm{OOH}^{\bullet} \longrightarrow \text { Degraded Products }
\end{gathered}
$$

$\mathrm{H}^{+}$has played an important role in the photocatalytic oxidation. In the weak acidity condition, $\mathrm{H}^{+}$can combine with active oxygen to produce more ${ }^{\circ} \mathrm{OH}$ which increases the reaction rate. In the neutral and alkaline condition, the oxidation electric potential decreased as the $\mathrm{pH}$ increases. As a result, the removal had a decline [19].

3.4.2. NBH Dosage Effect. The result of aniline degradation over NBH dosage was given in Figure 5. The result showed that the oxidation efficiency was increasing with $\mathrm{NBH}$ dosage increasing correspondingly in the first $30 \mathrm{~min}$. When $\mathrm{NBH}$ dosage was $0.5 \mathrm{~g}$, there was a significant rise in the removal, as the aniline concentration was decreased to $12.7 \mathrm{mg} / \mathrm{L}$ in the $10 \mathrm{~min}$. However, the removal in the $120 \mathrm{~min}$ was $84 \%$, lower when compared with $0.2 \mathrm{~g}$ and $0.1 \mathrm{~g}$, which were both around $87 \%$. Referring to the fact that over NBH dosage could hinder the suspension transparency, which would be an obstacle 


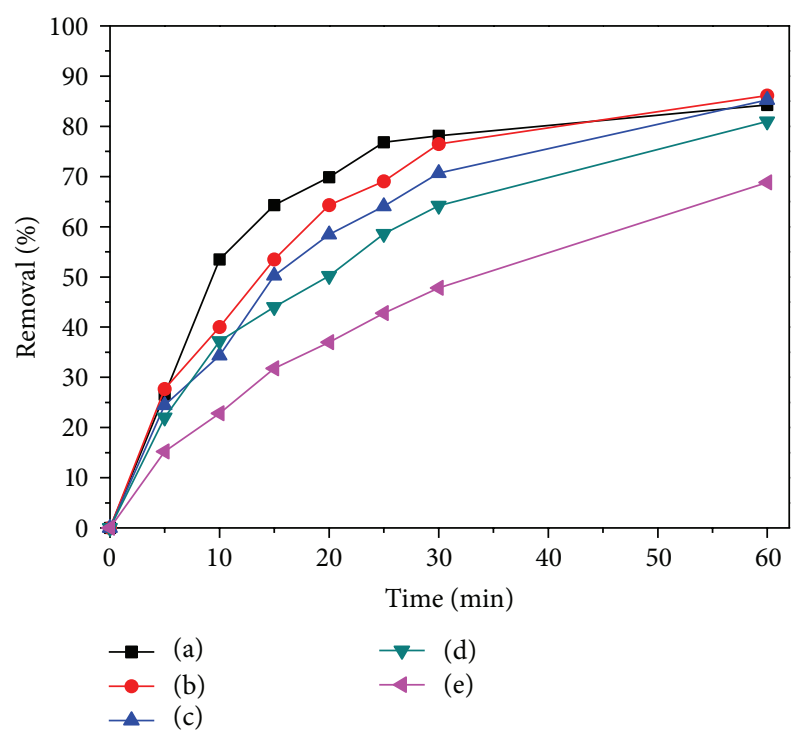

FIgURE 5: Effect amount of NBH. (a) $0.5 \mathrm{~g}$, (b) $0.2 \mathrm{~g}$, (c) $0.1 \mathrm{~g}$, (d) $0.05 \mathrm{~g}$, and (e) $0.025 \mathrm{~g}$.

to absorb light and decrease photocatalytic degradation efficiency eventually, as a result, excessive NBH dosage could lead to a downward trend shown in the oxidation effect.

3.4.3. GC/MS Analysis. In the given condition, aniline could be degraded completely in the $30 \mathrm{~min}$. Analysis on the intermediates and final products can help to clarify the details of the reaction. They were identified by GC/MS (GCMSQP2010 Plus) and shown in Table 1 and Figure 6.

In the chromatograph of initial sample, there was a peak representing aniline, which disappeared in the $30 \mathrm{~min}$. The chromatomap of $60 \mathrm{~min}$ resembled that of $30 \mathrm{~min}$, as the peak of $\mathrm{C}_{10} \mathrm{H}_{13} \mathrm{O}_{2} \mathrm{~N}$ and azobenzene existed, while their top area was decreasing. It proved that the above intermediates of aniline have been degraded to other products. There was a peak at about $7 \mathrm{~min}$ in the picture of $60 \mathrm{~min}$, which was $\mathrm{C}_{2} \mathrm{H}_{5} \mathrm{O}_{3} \mathrm{~N}$, the product of $\mathrm{C}_{10} \mathrm{H}_{13} \mathrm{O}_{2} \mathrm{~N}$ and azobenzene. In the chromatomap of $90 \mathrm{~min}, \mathrm{C}_{2} \mathrm{H}_{5} \mathrm{O}_{3} \mathrm{~N}$ was not detected, which meant it had been mineralized into $\mathrm{CO}_{2}$. The peak of $\mathrm{C}_{10} \mathrm{H}_{13} \mathrm{O}_{2} \mathrm{~N}$ had disappeared in the chromatomap of $120 \mathrm{~min}$. The organics containing nitrogen only was azobenzene, and its peak area had decreased to a small part.

The photohole, generated by $\mathrm{NaBiO}_{3}$ under visible light, could make reaction with aniline and produce azobenzene. Azobenzene produces $\mathrm{C}_{10} \mathrm{H}_{13} \mathrm{O}_{2} \mathrm{~N}$ by ${ }^{\circ} \mathrm{OH}$ and $\mathrm{h}^{+}$. As the reaction goes on, azobenzene could still react with ${ }^{\circ} \mathrm{OH}$ or $\mathrm{h}^{+}$until its loop opens. $\mathrm{C}_{10} \mathrm{H}_{13} \mathrm{O}_{2} \mathrm{~N}$ would go into two parts by the effect of ${ }^{\bullet} \mathrm{OH}$ and $\mathrm{h}^{+}$. One could produce $\mathrm{C}_{2} \mathrm{H}_{5} \mathrm{O}_{3} \mathrm{~N}$ and then be mineralized, while the other one is mineralized after ring opening.

\section{Conclusion}

Aniline could be easily degraded by $\mathrm{NaBiO}_{3}$ under visible light irradiation. In the experiment. Aniline was decomposed
TABLE 1: Identification of the small molecular intermediates of aniline during the photoreaction by GC/MS.

\begin{tabular}{lcccc}
\hline Product & $\begin{array}{c}\mathrm{Rt} \\
(\mathrm{min})\end{array}$ & $\mathrm{Mw}$ & Formula & Name \\
\hline 1 & 7 & 91 & $\mathrm{C}_{2} \mathrm{H}_{5} \mathrm{NO}_{3}$ & $\begin{array}{c}\text { 2-Nitroethanol } \\
\text { 3-Hydroxy-N- } \\
\text { phenylbutanamide }\end{array}$ \\
2 & 18 & 179 & $\mathrm{C}_{10} \mathrm{H}_{13} \mathrm{NO}_{2}$ & $\begin{array}{c}\text { Aniline } \\
3\end{array}$ \\
4 & 18.5 & 93 & $\mathrm{C}_{6} \mathrm{H}_{7} \mathrm{~N}$ & Azobenzene \\
\hline
\end{tabular}

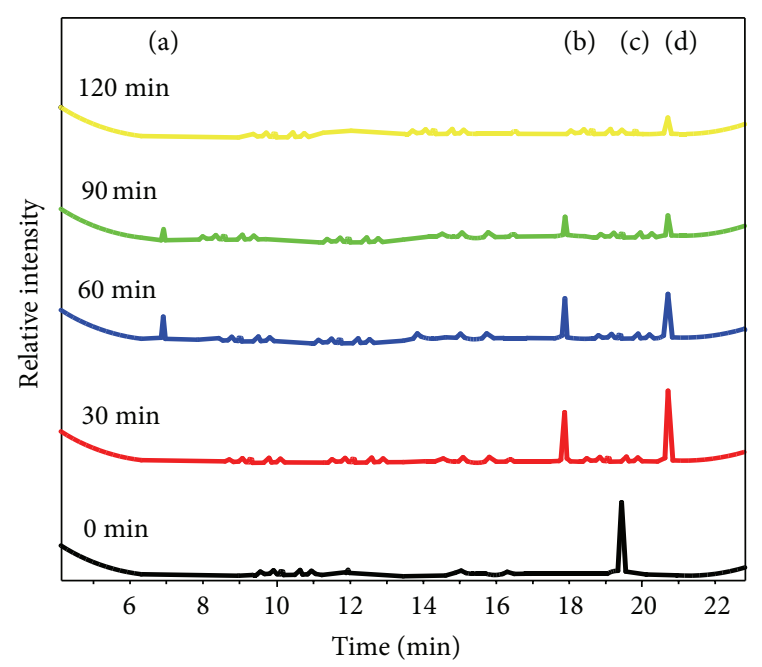

FIGURE 6: GC chromatograph of intermediates. (a) $\mathrm{C}_{2} \mathrm{H}_{5} \mathrm{O}_{3} \mathrm{~N}$, (b) $\mathrm{C}_{10} \mathrm{H}_{13} \mathrm{O}_{2} \mathrm{~N}$, (c) $\mathrm{C}_{6} \mathrm{H}_{7} \mathrm{~N}$, and (d) $\mathrm{C}_{12} \mathrm{H}_{10} \mathrm{~N}_{2}$.

largely under visible light over $\mathrm{NaBiO}_{3}$ in 120 min, which could reach $95 \%$ in some conditions. Moreover, three small molecular products were also identified by GC/MS. On the basis of the data collected, the mechanism of aniline photodegradation on $\mathrm{NaBiO}_{3}$ had been elucidated. Aniline could react with ${ }^{\circ} \mathrm{OH}$ or $\mathrm{h}^{+}$. Its products would go into two parts. One part would be mineralized directly, while the other part opened ring and produced $\mathrm{C}_{2} \mathrm{H}_{5} \mathrm{O}_{3} \mathrm{~N}$ then was mineralized; meanwhile, $\mathrm{N}$-ionogen turned into mineral nitrogen.

\section{Conflict of Interests}

The authors declare that there is no conflict of interests regarding the publication of this paper.

\section{Acknowledgments}

This research was supported by the National Natural Science Foundation of China (41272266), Natural Science Foundation of Jiangsu Province (BK2012732), and the Natural Science Key Program for Si Chuan Province Education Department of China (10ZA113). 


\section{References}

[1] M. Mitadera, N. Spataru, and A. Fujishima, "Electrochemical oxidation of aniline at boron-doped diamond electrodes," Journal of Applied Electrochemistry, vol. 34, no. 3, pp. 249-254, 2004.

[2] M. Fukushima, K. Tatsumi, and K. T. Morimoto, "The fate of aniline after a photo-fenton reaction in an aqueous system containing iron(III), humic acid, and hydrogen peroxide," Environmental Science \& Technology, vol. 34, no. 10, pp. 20062013, 2000.

[3] T. Kako and J. Ye, "Photocatalytic decomposition of acetaldehyde over rubidium bismuth niobates under visible light irradiation," Materials Transactions, vol. 46, no. 12, pp. 2694-2698, 2005.

[4] V. Mirkhani, S. Tangestaninejad, M. Moghadam, M. H. Habibi, and A. Rostami Vartooni, "Photodegradation of aromatic amines by Ag-Tio2 photocatalyst," Journal of the Iranian Chemical Society, vol. 6, no. 4, pp. 800-807, 2009.

[5] D. Chatterjee and S. Dasgupta, "Visible light induced photocatalytic degradation of organic pollutants," Journal of Photochemistry and Photobiology C, vol. 6, no. 2-3, pp. 186-205, 2005.

[6] D. Zhao, C. Chen, Y. Wang et al., "Enhanced photocatalytic degradation of dye pollutants under visible irradiation on $\mathrm{Al}(\mathrm{III})$-modified $\mathrm{TiO}_{2}$ : structure, interaction, and interfacial electron transfer," Environmental Science \& Technology, vol. 42, no. 1, pp. 308-314, 2008.

[7] E. Borgarello, J. Kiwi, M. Gratzel et al., "Visible light induced water cleavage in colloidal solutions of chromium-doped titanium dioxide particles," Journal of the American Chemical Society, vol. 104, no. 11, pp. 2996-3002, 1982.

[8] N. Serpone, D. Lawless, J. Disdier, and J.-M. Herrmann, "Spectroscopic, photoconductivity, and photocatalytic studies of TiO2 colloids: Naked and with the lattice doped with $\mathrm{Cr} 3+$, Fe3+, and V5+ cations," Langmuir, vol. 10, no. 3, pp. 643-652, 1994.

[9] H. Kato, H. Kobayashi, and A. Kudo, "Role of Ag+ in the band structures and photocatalytic properties of AgMO3 (M: Ta and $\mathrm{Nb}$ ) with the perovskite structure," Journal of Physical Chemistry $B$, vol. 106, no. 48, pp. 12441-12447, 2002.

[10] Z. Zou, J. Ye, and H. Arakawa, "Structural properties of $\mathrm{InNbO}_{4}$ and $\mathrm{InTaO}_{4}$ : correlation with photocatalytic and photophysical properties," Chemical Physics Letters, vol. 332, no. 3-4, pp. 271$277,2000$.

[11] Z. Li, N. Xu, Y. Chen, and Z. Zou, "Photocatalytic behavior of a new series of photocatalysts, $\mathrm{Ba}_{2} \mathrm{Bi}^{(V)} \mathrm{Bi}^{(I I I)} \mathrm{O}_{6}$ and $\mathrm{Ba}_{2} \mathrm{Sb}^{(V)} \mathrm{Bi}^{(I I I)} \mathrm{O}_{6}$ ", Research on Chemical Intermediates, vol. 31, no. 4-6, pp. 529-534, 2005.

[12] J. Kou, H. Zhang, Z. Li, S. Ouyang, J. Ye, and Z. Zou, "Photooxidation of polycyclic aromatic hydrocarbons over $\mathrm{NaBiO}_{3}$ under visible light irradiation," Catalysis Letters, vol. 122, no. 1-2, pp. 131-137, 2008.

[13] K. Yu, S. Yang, S. A. Boyd, H. Chen, and C. Sun, "Efficient degradation of organic dyes by BiAgxOy," Journal of Hazardous Materials, vol. 197, pp. 88-96, 2011.

[14] J.-Q. Pan, P.-Y. Wan, Y.-Z. Sun, Z.-H. Wang, and X.-G. Liu, "Synthesis and structural characterization of nano-NaBiO3," Gaodeng Xuexiao Huaxue Xuebao/Chemical Journal of Chinese Universities, vol. 25, no. 12, p. 2204, 2004.

[15] T. Hiroaki, A. Manabu, K. Yasuyaki, and I. Seishiro, "Enhancing effect of $\mathrm{SiO}_{x}$ monolayer coverage of $\mathrm{TiO}_{2}$ on the photoinduced oxidation of rhodamine $6 \mathrm{G}$ in aqueous media," The Journal of Physical Chemistry B, vol. 102, no. 33, pp. 6360-6366, 1998.
[16] D. D. Dionysiou, A. P. Khodadoust, A. M. Kern et al., "Continuous-mode photocatalytic degradation of chlorinated phenols and pesticides in water using a bench-scale $\mathrm{TiO}_{2}$ rotating disk reactor," Applied Catalysis B, vol. 24, no. 3-4, pp. 139-155, 2000.

[17] I. K. Konstantinou, T. M. Sakellarides, V. A. Sakkas et al., "Photocatalytic Degradation of Selected s-Triazine Herbicides and Organophosphorus Insecticides over Aqueous TiO2 Suspensions," Environmental Science and Technology, vol. 35, no. 2, pp. 398-405, 2001.

[18] H. Wu, M. Wu, M. Xie et al., "The enhanced electro-assisted photocatalytic degradation of organic water contaminants," Chinese Journal of Catalysis, vol. 21, no. 5, pp. 399-403, 2000.

[19] P. K. Malik, "Oxidation of safranine T in aqueous solution using Fenton's reagent: involvement of an $\mathrm{Fe}$ (III) chelate in the catalytic hydrogen peroxide oxidation of safranine T," The Journal of Physical Chemistry A, vol. 108, no. 14, pp. 2675-2681, 2004. 

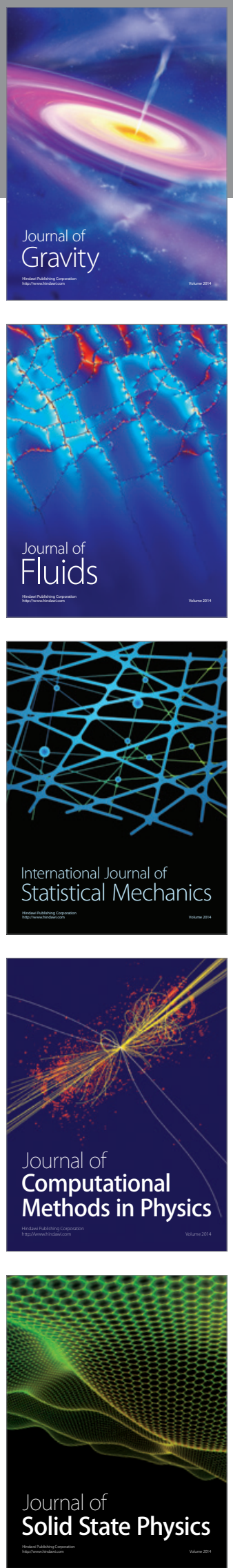

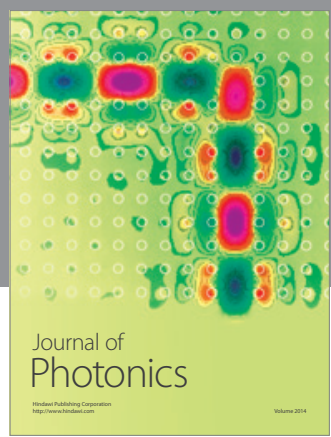

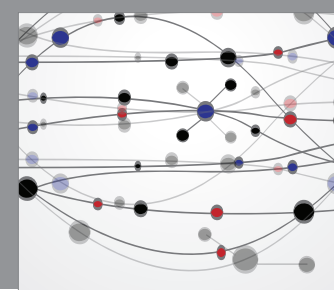

The Scientific World Journal

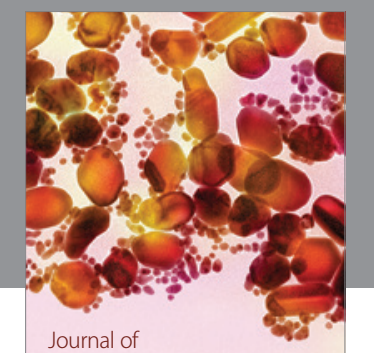

Soft Matter
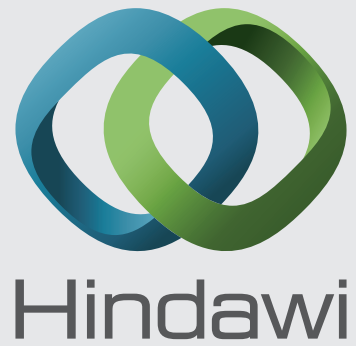

Submit your manuscripts at

http://www.hindawi.com
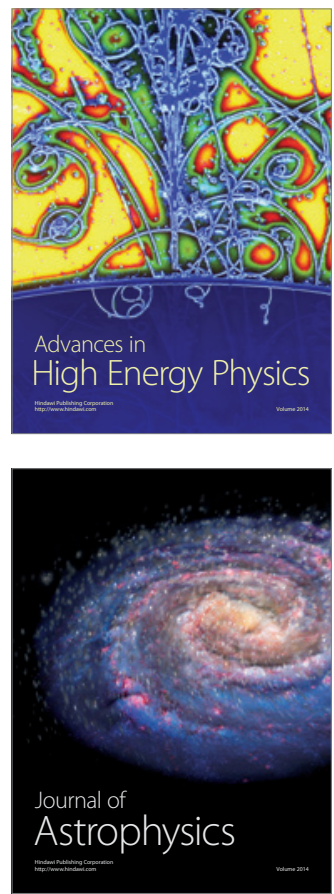
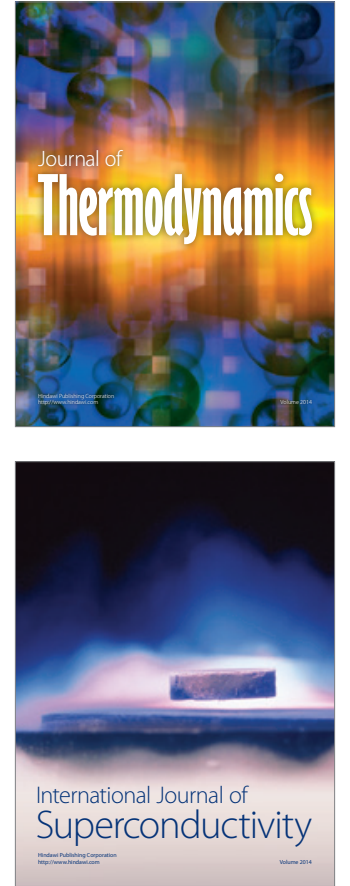
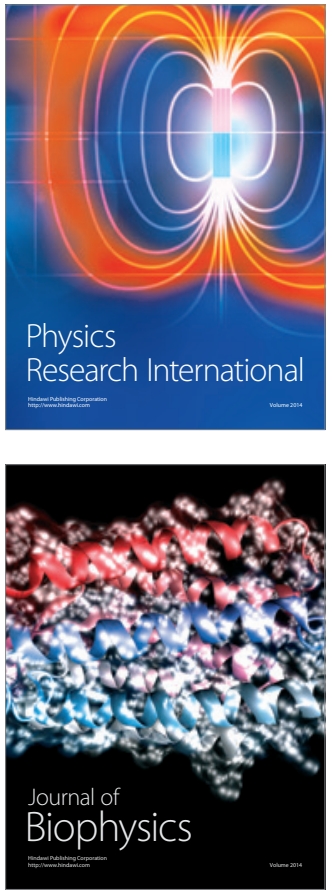
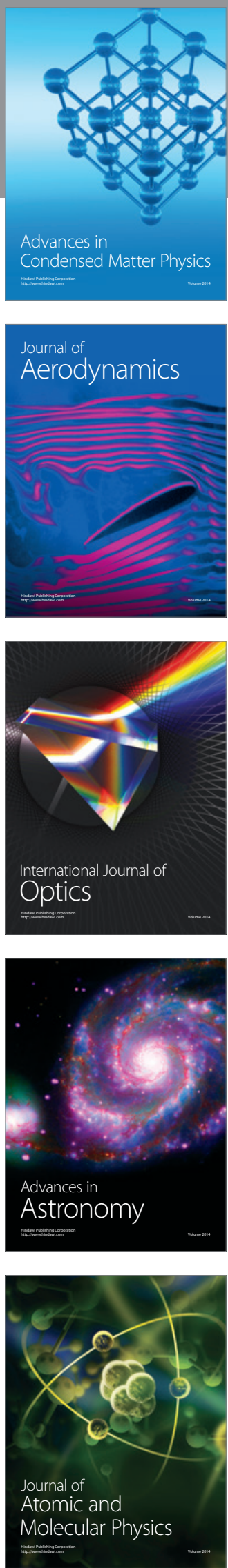